\title{
Body Mass Index, Neighborhood Fast Food and Restaurant Concentration, and Car Ownership
}

\author{
Sanae Inagami, Deborah A. Cohen, Arleen F. Brown, and Steven M. Asch
}

\begin{abstract}
Eating away from home and particularly fast food consumption have been shown to contribute to weight gain. Increased geographic access to fast food outlets and other restaurants may contribute to higher levels of obesity, especially in individuals who rely largely on the local environment for their food purchases. We examined whether fast food and restaurant concentrations are associated with body mass index and whether car ownership might moderate this association. We linked the 2000 US Census data and information on locations of fast food and other restaurants with the Los Angeles Family and Neighborhood Study database, which consists of 2,156 adults sampled from 63 neighborhoods in Los Angeles County. Multilevel modeling was used to estimate associations between body mass index (BMI), fast food and restaurant concentration, and car ownership after adjustment for individual-level factors and socioeconomic characteristics of residential neighborhoods. A high concentration of local restaurants is associated with BMI. Car owners have higher BMIs than non-car owners; however, individuals who do not own cars and reside in areas with a high concentration of fast food outlets have higher BMIs than non-car owners who live in areas with no fast food outlets, approximately $12 \mathrm{lb}$ more $(p=0.02)$ for an individual with a height of $5 \mathrm{ft} .5 \mathrm{in}$. Higher restaurant density is associated with higher BMI among local residents. The local fast food environment has a stronger association with BMI for local residents who do not have access to cars.
\end{abstract}

KEYWORDS Multilevel, Fast food, BMI, Obesity, Mobility, Neighborhood, Restaurant

\section{INTRODUCTION}

In $2003,41 \%$ of family food budgets in the USA were spent eating out. ${ }^{1}$ Fast food sales, which comprise more than $41 \%$ of restaurant sales, have increased from $\$ 16.1$ billion in 1975 to $\$ 123.9$ billion in $2003,{ }^{1}$ and because consumption of fast food is associated with higher body mass index (BMI) in adults and children, ${ }^{2-4}$ there has been recent interest in understanding whether fast food consumption is causally related to the US obesity epidemic. ${ }^{2-7}$

Inagami is with the General Internal Medicine, Center for Health Equity Research and Promotion (CHERP) of the VA Pittsburgh Healthcare System and University of Pittsburgh in Pittsburgh, Pittsburgh, PA, USA; Cohen is with the Health, RAND Corporation, Santa Monica, CA, USA; Brown is with the General Internal Medicine, University of California, Los Angeles, Los Angeles, CA, USA; Asch is with the HSR\&D, VA Greater Los Angeles Healthcare System and University of California, Los Angeles, CA, USA.

Correspondence: Sanae Inagami, MD, MPH, General Internal Medicine, Center for Health Equity Research and Promotion (CHERP) of the VA Pittsburgh Healthcare System and University of Pittsburgh in Pittsburgh, Pittsburgh, PA, USA. (E-mail: sanae.inagami@va.gov) 
It is unclear whether proximity to fast food outlets can explain the higher prevalence of obesity in low-income minority populations. Studies examining the location of outlets in relation to at-risk populations in Europe and the USA have yielded mixed results ${ }^{8-14,37,41-43}$; furthermore, the association between access to fast food restaurants and obesity has also been mixed. ${ }^{5,7,15-17,37-40}$ Mehta and Chang $^{5}$ found an association between higher US county concentration of fast food restaurants and increased $\mathrm{BMI}$; they also found that higher county concentration of full-service restaurants and total restaurants (fast food + full service restaurants) were associated with lower BMI. In another US study, Chou et al. ${ }^{7}$ found that higher concentration of total restaurants at the state level made the largest contribution to increasing weight. All the other cited studies showed no association between obesity and geographic access to fast food restaurants.

One reason for the mixed results in fast food studies may be due to how access and proximity are measured. Studies have used distance to the nearest fast food site $^{15}$ and number of fast food outlets per 1,000 people $^{16,17}$ to measure fast food exposure. Distance to the closest fast food site may be insensitive in measuring spatial accessibility in congested urban areas where one may find many fast food outlet options at similar distance from any reference point. Additionally, fast food per population measure is a supply ratio that grossly compares supply of fast food between different areas, which may misrepresent access because it does not incorporate any measure of distance or travel impedance. ${ }^{18}$ Concentration of fast food outlets as measured by locations per roadway mile may be a more appropriate measure of fast food access in modern urban environments because it accounts for spatial dispersion, ${ }^{19,20}$ which captures not only the fast food environment but its interaction with people. ${ }^{21}$ This may be particularly relevant in cities where individuals traverse the city and access fast food outlets along major and minor arterial roadways. Studies of alcohol outlet density measures have used alcohol outlet stores per roadway miles to show an association with violent assaults and with alcohol-related motor vehicle accidents. ${ }^{22,23}$

Related to this issue, fast food associations with BMI may not have been seen if factors, such as car ownership, that reduce barriers to alternative healthier food choices were not taken into account. Early studies have shown that neighborhood associations with health outcomes are stronger in individuals who do not own cars. ${ }^{27,44}$ No study has yet examined the role of car ownership in the association between access to fast food and obesity.

In this multilevel study, we examined whether fast food and general restaurant access, defined as the number of fast food outlets (or restaurants) per roadway miles per residential census tract, is associated with neighborhood socioeconomic levels and the BMI of its residents and whether this association is moderated by car ownership.

\section{MATERIALS AND METHODS}

\section{Sample}

The Los Angeles Family and Neighborhood Survey (L.A.FANS) is a longitudinal study that was undertaken to understand how neighborhoods affect a variety of outcomes, including health in adults. We used data from L.A.FANS 2000-2001, the first wave of the study, a stratified random sample of 65 neighborhoods (census tracts from the 1990 Census) in Los Angeles County designed to oversample poor neighborhoods or those census tracts with a high proportion of residents living below the poverty line. Twenty 
tracts were selected from the very poor group (the top 10\% of the poverty distribution in Los Angeles County), 20 from the poor strata (tracts in the 60th-89th percentile) and the remaining 25 tracts comprise the non-poor (tracts in the bottom $60 \%$ of the distribution). The choice of three strata and the specific cutoffs were based on analysis that examined the trade-off under different schemes between likely yield of welfare recipients and the concentration of the sample in a small number of high poverty areas. $^{24}$ The household survey asked adults about household economic status, education, employment, income, marital history, and neighborhoods of residence. We eliminated respondents for whom either income $(n=37)$ or BMI $(n=273)$ was missing and for whom BMI was $>47(n=10)$ as well as those who listed their income as " 0 " but who were also employed $(n=23)$. We also eliminated "other race/ethnicity" $(n=74)$ because of small sample size. Our final sample size was 2,156 after eliminating two very large census tracts $(n=88)$ that differed substantially from other tracts that were sampled, with areas larger than 126,000 acres and roadway miles greater than 350 miles. With these two tracts deleted, the largest census tract was 2,467 acres and contained 79 roadway miles.

Residential neighborhoods were identified at the census-tract level. The L.A. FANS sampling strategy was based on census tract boundaries identified from the 1990 Census (before data from the 2000 Census was available). When the survey was undertaken, in 2000-2001, data were extracted from the 2000 decennial census file. Because the 2000 census tract boundaries were somewhat different from the 1990 census tract boundaries, we computed census tract values for the old boundaries as a population-weighted average of all new census tracts falling within the old boundaries (only the population of the new census tract that falls within the old boundaries is used in constructing weights). For example, if a 1990 census tract was split into two 2000 census tracts, we computed a weighted average of the two census tracts where the weights are proportional to the 2000 tract population.

\section{Measures}

Dependent Variable Respondents were asked to provide their height and weight; from this information, each respondent's BMI was calculated in kilograms per square meter. BMI was analyzed as a continuous outcome.

Fast Food Restaurants We obtained a list of all restaurants in Los Angeles County from the L.A. County Department of Public Health, Environmental Health Division and used the 1997 North American Industry Classification system codes to identify fast food restaurants (limited-service restaurants considered chains or franchises). Data on the fast food outlets were merged with individual-level data using census tracts (see Appendix A for complete list of outlets included). The number of fast food outlets within a census tract was divided by census tract roadway miles to create a fast food density measure for each census tract. Roadway miles came from Department of Commerce-2000 Census boundary files.

The fast food density measure was divided into three groups. The reference group included all census tracts with no fast food outlets. The second and third groups were created by dividing the remaining census tracts at the midpoint, defined as "low fast food density" (range, 0.025-0.15 fast food outlets/roadway miles) and "high fast food density" (range, 0.16-0.43 fast food outlets/roadway miles). 
Other Food Outlets Total food outlets per roadway miles within the census tract were also calculated using the list of all restaurants provided by the L.A. County Department of Public Health, Environmental Health Division. We specifically excluded restaurants that did not have public access, such as catering businesses, and those that were located within sports arenas, private clubs, cinemas, senior citizen centers, airports and hotels; we also excluded restaurants that were located in bars, pool halls, stores such as Kmart and Target, and restaurants within supermarkets (i.e., delis and bakeries).

The total restaurant measure was divided into three groups. The reference group included all census tracts with no restaurants. The second and third groups were created by dividing the remaining census tracts at the midpoint, defined as "total restaurants: low density" (range, 0.04-0.57 restaurants/roadway miles) and "total restaurants: high density" (range, 0.59-9.93 restaurants/roadway miles). The total restaurant measure included fast food outlets.

Residential Neighborhood Disadvantage Four summary statistics of census tracts in Los Angeles County were each standardized and combined to create a neighborhood "disadvantage score," a well-described and often-used measure of socioeconomic status $(\mathrm{SES})^{25}$ : (1) percent living below the poverty line, (2) percent of households that are headed by a woman, (3) percent male unemployment, and (4) percent of families receiving public assistance. The continuous disadvantage score of residential neighborhoods was used for regression analysis, lower scores referring to higher SES areas. The score was categorized into four quartiles based on the distribution of all census tracts in Los Angeles and referred to as Very Low (the most disadvantaged), Lower Middle, Upper Middle, and Very High SES areas for Tables 1 and 2.

Car Ownership Respondents were asked in the survey whether or not they or their spouse/partner had one or more working cars. Car ownership was separated into two categories, those who had access to a working car and those who did not; the reference category refers to those respondents who did not have access to a working car.

Sociodemographic Controls Models were controlled for (1) gender; (2) age (logged); (3) education; (4) race/ethnicity (Latino, African-American, Asian, white); (5) employment; (6) marital status; (7) annual household income (logged); (8) immigrant status; and (9) car ownership (respondent or spouse/partner owns one or more working cars).

Weights The study used a multistage stratified sample design in which tracts, blocks within tracts, and households within tracts were sampled. Tracts were stratified by the percentage of the population in the tract who were in high poverty and by whether household included children under age 18 . Sampling weights provided by L.A.FANS reflect both unequal probabilities of sample selection and household nonresponse. ${ }^{24}$ Weights were used as probability weights in HLM 6.02 (2004). ${ }^{26}$

\section{Statistical Analyses}

Multilevel weighted linear regression models using HLM $6.02(2004)^{26}$ were used to estimate simultaneously the association between BMI and the individual sociodemographic variables and residential neighborhood characteristics. 
TABLE 1 Individual characteristics of respondents: L.A.FANS 2000-2001

\begin{tabular}{|c|c|}
\hline Characteristics & Values \\
\hline Total Sample & 2,156 \\
\hline \multicolumn{2}{|l|}{ Family income (\$) } \\
\hline Median (range) & $26,550(0-1,303,000)$ \\
\hline Mean (range) & 52,338 \\
\hline \multicolumn{2}{|l|}{ Age } \\
\hline Mean (range) & $39.4(18-91)$ \\
\hline \multicolumn{2}{|l|}{ BMI } \\
\hline Mean (range) & $26.6(14.2-46.6)$ \\
\hline$\%$ Married & 50 \\
\hline$\%$ Own car & 76 \\
\hline$\%$ Female & 57.6 \\
\hline \% Employed & 66 \\
\hline$\%$ College & 20 \\
\hline \% Immigrant & 57 \\
\hline \multicolumn{2}{|l|}{ Race/ethnicity } \\
\hline Latino & $1,243(58)^{a}$ \\
\hline African-American & $198(9)^{\mathrm{a}}$ \\
\hline White & $552(26)^{a}$ \\
\hline Asian & $158(7)^{\mathrm{a}}$ \\
\hline \multicolumn{2}{|l|}{ Residential area SES } \\
\hline Very Low & $824(38)^{a}$ \\
\hline Lower Middle & $651(30)^{a}$ \\
\hline Upper Middle & $346(16)^{a}$ \\
\hline Very High & $335(16)^{a}$ \\
\hline \multicolumn{2}{|c|}{ Concentration fast food } \\
\hline High & $563(26)^{a}$ \\
\hline Low & $409(19)^{a}$ \\
\hline Zero & $1,184(55)^{\mathrm{a}}$ \\
\hline \multicolumn{2}{|c|}{ Concentration total restaurant } \\
\hline High & $868(40)^{a}$ \\
\hline Low & $874(41)^{a}$ \\
\hline Zero & $414(19)^{a}$ \\
\hline
\end{tabular}

${ }^{\mathrm{a}} \mathrm{N}$ (\% total sample)

Cross level interactions between fast food/total restaurant concentration (level 2) and car ownership (level 1) were examined to determine whether car ownership moderated the effect of fast food concentration on BMI.

\section{RESULTS}

\section{Descriptive Statistics}

The 2,156 L.A.FANS respondents were predominantly young (mean age 39 years) and Latino $(58 \%)$ as shown in the last column of Table 1 . Thirty-eight percent of the adult sample resided in the lowest SES neighborhood quartile; nearly $70 \%$ of the total sample lived in the two lowest SES neighborhood quartiles.

Respondents missing BMI information had lower median income and were significantly $(p<0.05)$ less likely to own a car, less likely to live in a Very High SES Area, and less likely to be white, employed, and college educated. Concentration of neighborhood fast food establishments did not differ between those missing and those not missing BMI information. 
TABLE 2 Measures of the fast food environment in the 63 census tracts* included in the analyses L.A.FANS 2000-2001

\begin{tabular}{|c|c|c|c|c|c|}
\hline & Very Low & Lower Middle & Upper Middle & Very High & Total \\
\hline \# Census tracts & 25 & 19 & 10 & 9 & 63 \\
\hline \multicolumn{6}{|c|}{ \# Total restaurants/tract } \\
\hline Mean (SD) & $9.1(10.9)$ & $15.7(15.4)$ & $15.3(16.5)$ & $5.7(8.1)$ & $11.6(13.8)$ \\
\hline Range & $0-58$ & $0-58$ & $0-52$ & $0-23$ & $0-58$ \\
\hline \multicolumn{6}{|l|}{ \# Fast food/tract } \\
\hline Mean (SD) & $0.6(1.2)$ & $1.7(1.9)$ & $2.2(2.4)$ & $1.6(1.9)$ & $1.3(1.9)$ \\
\hline Range & $0-4$ & $0-6$ & $0-8$ & $0-5$ & $0-8$ \\
\hline \multicolumn{6}{|c|}{ \# Fast food/roadway miles/tract } \\
\hline Mean (SD) & $0.05(0.10)$ & $0.12(0.14)$ & $0.10(0.08)$ & $0.09(0.12)$ & $1.3(1.9)$ \\
\hline Range & $0-0.35$ & $0-0.43$ & $0-0.23$ & $0-0.37$ & $0-0.43$ \\
\hline \multicolumn{6}{|c|}{ Roadway miles/tract } \\
\hline Mean (SD) & $15(7.6)$ & $17(13)$ & $20(6.2)$ & $24(11)$ & $17.8(10.4)$ \\
\hline Range & $6-37$ & $9-79$ & $13-35$ & $9-46$ & $6-79$ \\
\hline \multicolumn{6}{|l|}{ Acres/tract } \\
\hline Mean (SD) & 389 (382) & 425 (431) & 559 (317) & 866 (553) & 498 (448) \\
\hline Range & $83-1,664$ & $159-2,467$ & $245-1,223$ & $176-1,725$ & $83-2,467$ \\
\hline
\end{tabular}

*Two census tracts were eliminated. These census tracts had disproportionately large acreages (126,000 and 129,714 acres) and roadway miles (726 and 355 miles) compared to other census tracts. The largest census tract in the sample used for analysis contains 2,467 acres and 79 roadway miles.

\section{Fast Food and other Restaurant Locations}

On average, Lower Middle SES census tracts had the highest total number of restaurants (15.7); Very High SES areas had the least, 5.7 (see Table 2). The number of restaurant establishments per roadway miles remained highest in the Lower Middle SES areas and lowest in the Very High SES areas.

On average, Upper Middle SES census tracts had the highest absolute number of fast food outlets, with 2.2 outlets; Very Low SES areas had the least, with 0.6 outlets (see Table 2). However, because census tract acreage and roadway miles increase as SES increases, the density of fast food outlets (per roadway mile) was highest in Lower Middle SES areas: 0.12 fast food outlets/roadway mile.

\section{Multilevel Analyses}

Individual and neighborhood factors associated with BMI are shown in Table 3. Model A examines the role of total restaurant density, and model $\mathrm{B}$, fast food outlet density; model $\mathrm{C}$ examines the interaction between car ownership and fast food outlet density, and model $\mathrm{D}$ examines the interaction between car ownership and total restaurant density. All models in Table 3 show that BMI was positively associated with car ownership and being Latino, older, and female.

Model A shows that higher density of total restaurants was associated with about a 1.0 BMI unit increase in residents who lived in the same census tract. In contrast to total restaurants, neither high nor low concentration of fast food outlets was associated with BMI (see model B). However, when we included the interaction between fast food establishments and car ownership (model C), residents living within an area of high fast food concentration were found to weigh $2.03 \mathrm{BMI}$ units more than residents living in areas with no fast food outlets; this effect was nearly erased in those residents who owned cars living in areas with high fast food concentration (-1.86 BMI units). In addition, model fit was significantly improved (a decrease in deviance of two/variable is considered a statistically significant 


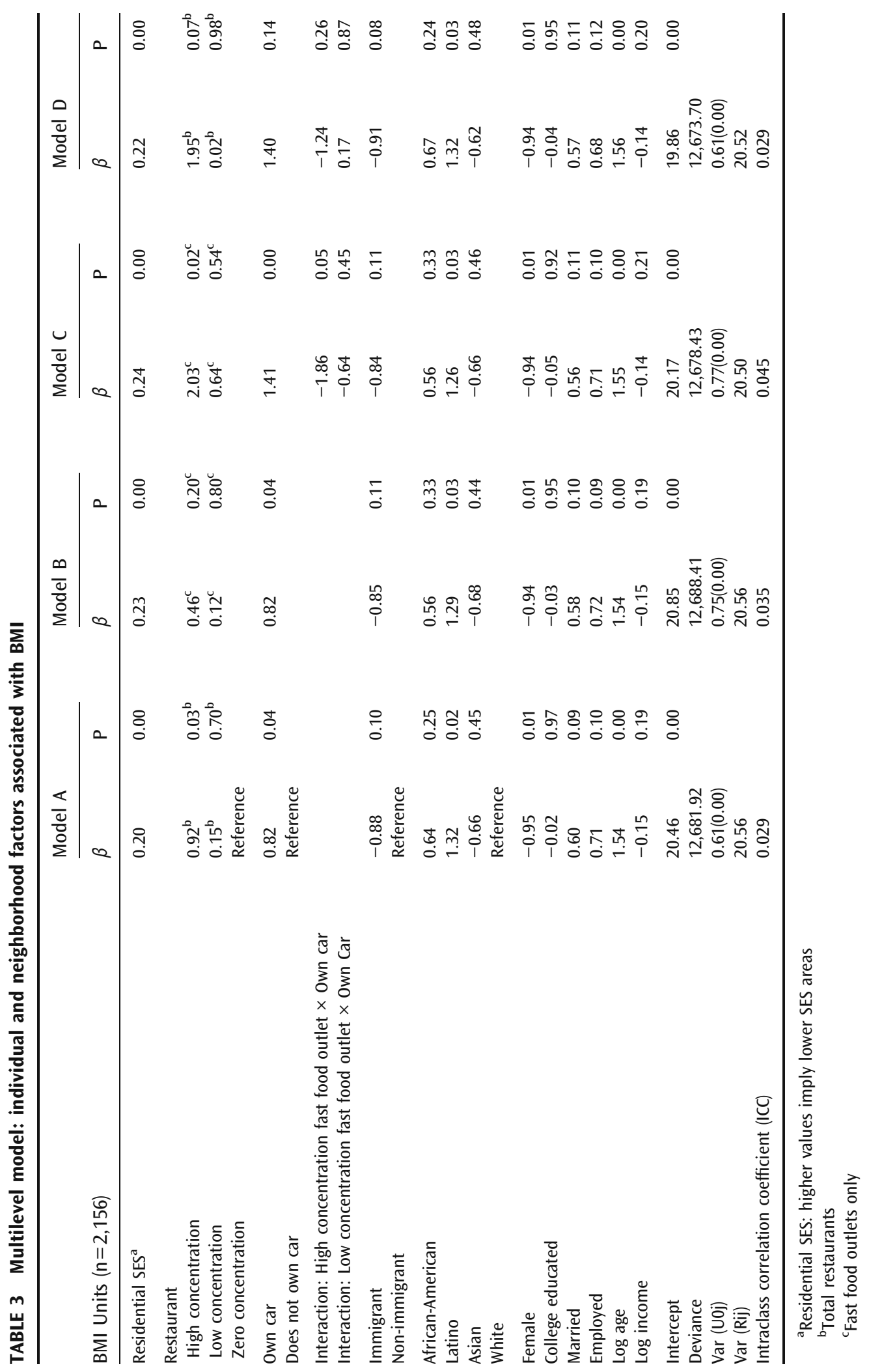


TABLE 4 Predicted change in weight for a person $5 \mathrm{ft} 5 \mathrm{in}$. tall

\begin{tabular}{ll}
\hline Characteristic & ${\text { Change in predicted weight }(\mathrm{Ib})^{\mathrm{a}}}^{\mathrm{a}}$ \\
\hline Gender & -5.6 \\
Race/ethnicity & +7.6 \\
Latino (vs. white) & $\mathrm{NS}$ \\
African-American (vs. white) & $\mathrm{NS}$ \\
Asian (vs. white) & +9.5 \\
Owns car & +8.5 \\
High fast food concentration & \\
Zero fast food concentration & +12.2 \\
Does not own car & 0 \\
High fast food concentration & \\
Zero fast food concentration & \\
\hline
\end{tabular}

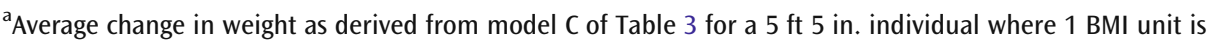
equivalent to approximately $6 \mathrm{lb}$
}

improvement in model fit). Though including the interaction between total restaurants and car ownership improved model fit, the interaction was not significant and did not change the association between BMI and total restaurant concentration. Eighty percent of respondents who lived in areas with high fast food concentration and $75 \%$ in areas with low fast food concentration owned cars; $73 \%$ of those who lived in areas with no fast food establishments owned cars.

Table 4 estimates the impact of fast food concentration (from model C) on weight for a reference individual who is $5 \mathrm{ft} 5 \mathrm{in}$. tall, in whom $1 \mathrm{BMI}$ unit would be equivalent to about $6 \mathrm{lb}$. Women who are $5 \mathrm{ft} 5 \mathrm{in}$. would weigh $5.6 \mathrm{lb}$ less than a $5 \mathrm{ft} 5 \mathrm{in}$. man. Those of Latino ethnicity would be approximately $7.6 \mathrm{lb}$ greater in weight compared to whites. Car owners on average weigh $8.5 \mathrm{lb}$ more than non-car owners. Non-car owners who live in areas of high fast food concentration weigh $12 \mathrm{lb}$ more than non-car owners who live in areas without fast food outlets and 2.7 lb (0.45 BMI units) more than car owners who live in areas of high fast food concentration. Those who do not own cars who live in areas without any fast food outlets (reference group) weigh the least (low concentration of census tract fast food alone was not associated with BMI). We found no significant interactions between race/ethnicity and immigration status. We also found no interactions between gender and car ownership, between gender and concentration of fast food, between gender and African-American race $(\beta=0.88 ; p=0.49)$, nor between gender and Asian ethnicity $(\beta=-1.93 ; p=0.10)$. We did note an interaction effect between Latino race and female gender $(\beta=1.21 ; p=0.034)$, suggesting that increased weight in Latinos associated with proximity to restaurants is manifested by increased weight in women alone. Introducing the gender interaction with race/ethnicity did not alter the association between fast food and BMI nor the association among fast food, car ownership, and BMI. Though these interactions for the most part were not statistically significant, we suspect that, given greater power, there may be more gender, race/ethnicity, car ownership, and environmental interactions.

We also explored other measures to characterize the fast food environment. The number of fast food outlets/census tract area behaved similarly to fast food/ roadway miles. In contrast, number of fast food outlets/population density was not associated with BMI. We did not measure distance to nearest fast food establishment for this analysis. 


\section{DISCUSSION}

Our study supports the possibility that local food environments influence the risk of obesity, especially among adults without cars and living in proximity to a large number of fast food outlets. ${ }^{27}$ Those able to travel farther may have wider access to healthier food products, while those limited to their neighborhoods may be more likely to purchase energy-dense foods that contribute to weight gain. ${ }^{28-31}$ While all residents appear to be affected by the concentration of restaurants, the magnitude of the magnitude of effect of fast food outlets is much smaller for residents able to travel by car than for individuals without cars. Car ownership may reduce the local effect of fast food outlets in the neighborhood, while lack of car access appears to exacerbate it. Those who do not own cars may be more likely to visit fast food outlets than most costly full-service restaurants in their neighborhood.

Our use of roadway miles as a measure of fast food and restaurant density in Los Angeles suggests that measures of access by car or by foot for day-to-day activities may be a more relevant measure of exposure than the number of fast food establishments per population density or most proximate fast food location. The measure appears to be particularly germane in urban environments where fast food establishments may be located along roads in strip mall developments. However, these findings may not be applicable to data from Europe or in cities with high population density and with well-developed public transportation systems. Furthermore, our findings underscore the need to take local development and planning patterns into account when considering neighborhood effects on public health indicators.

Our study showed that total restaurant concentration was associated with higher BMI, whereas Mehta and $\mathrm{Chang}^{5}$ found that it was associated with lower BMI. Two factors may explain the different outcomes in our study; they did not include car ownership in their models and also analyzed their data the level of the county. While Mehta and Chang ${ }^{5}$ focused on county differences in BMI of its residents, our study focused on the differences in the local environments within one county and sought to explain whether these local differences were associated with the differences in BMI amongst disparate populations. Our study suggests that it is the widespread easy access to prepared food locally, regardless of whether or not it is "fast food," that is associated with increased weight, but that "fast food" appears to be particularly associated to increased weight in residents not owning cars. Though populations within urban counties like Los Angeles are increasing in weight, urban residents have been shown to have lower BMI compared to their rural counterparts $^{32-34}$; this may explain Mehta and Chang's findings that showed lower BMI in residents of counties with greater number of total restaurants.

Although some studies have found fast food access to be more concentrated in low-income and ethnic minority areas, ${ }^{8-10}$ in our study the density of fast food outlets appears to be more concentrated in middle-income areas and least concentrated in the lowest income areas. ${ }^{12,13}$ Therefore, fast food access alone cannot explain residential SES associations with BMI in Los Angeles. The food environment is complex, and exposure to different types of food outlets depends upon both urban design and access to transportation.

\section{Limitations}

The study is cross-sectional in nature and thus cannot prove causality. Our study cannot determine whether the effect we are seeing using the fast food measure is due to fast food access specifically or general access to restaurants or to other factors 
related to commercial development. In addition, detailed individual information regarding measures of the specific food eaten and physical activity was not available. Another concern is that self-reported height and weight are often underestimated and vary significantly among different race/ethnic groups ${ }^{35}$ and gender. ${ }^{36}$ However, underestimation would most likely underestimate the associations found in our study; on the other hand, variations in self-report among different race/ethnic groups would bias our study in directions unknown. While eliminating those missing BMI could have biased the results, they were equally distributed among the groups residing in high and low fast food concentration areas, so the likelihood of bias resulting from confounding is reduced. Bias may also result from the sampling strategy used, but weights were used to offset oversampling from poor areas in Los Angeles County. Lastly, boundaries that affect people's health are not necessarily fixed within census tracts.

\section{CONCLUSIONS}

Combating the obesity epidemic requires an understanding of the factors that contribute to it, both at the individual and neighborhood level. Those residents most vulnerable to barriers to healthy eating in their local food environment appear to be those who do not own cars. The relationship of access to fast food and BMI, illuminated by the interaction with car ownership, suggests that limiting fast food density, especially where a large proportion of the population do not have cars, may be an important measure to help curb the obesity epidemic. Facing higher levels of obesity and diabetes levels and the highest concentrations of fast food restaurants, the City Council currently is considering a proposal to ban new fast food restaurants in South Los Angeles.

\section{ACKNOWLEDGMENTS}

We are indebted to Aimée Bower for statistical programming. We thank ATS statistical consulting group for assistance with statistical modeling. We thank Los Angeles County Department of Public Health-Terrance Powell, Bureau Director Food Inspection Bureau and Michael Doom Environmental Health Specialist IV, MIS.

This study was supported in part by HRSA-MCH Grant \# R40MC00303 (Deborah Cohen, PI) and the Department of Veterans Affairs, Veterans Health Administration, Office of Research and Development, and is the result of work supported with resources and the use of facilities at the Center for Health Equity Research and Promotion at VA Pittsburgh Healthcare System in Pittsburgh, PA.

OPEN ACCESS This article is distributed under the terms of the Creative Commons Attribution Noncommercial License, which permits any noncommercial use, distribution, and reproduction in any medium, provided the original author(s) and source are credited.

\section{APPENDIX A}

Fast food establishments: McDonald's, Starbucks, Baskin-Robbins, Carl's Jr., Burger King, Taco Bell, Jack in the Box, Arby's, 7-Eleven, Subway, In-N-Out Burger, Kentucky Fried Chicken, Domino's Pizza, El Pollo Loco, Panda Express, Pizza Hut, 
Quiznos, Little Caesar's Pizza, Der Wienerschnitzel, Winchell's Donuts, Popeye's Chicken, Papa John's Pizza, Wendy's, Baja Fresh Mexican Grill, Hong Kong Express, Yoshinoya, Del Taco, Pizza Man, China Express, Tacos Mexico, Togo's Eatery, Round Table Pizza, Fatburger, La Salsa.

\section{REFERENCES}

1. Commercial Finance GE. 2005 Chain Restaurant Industry Review. Accessed on August 20, 2006. Available at: http://www.cefcorp.com/commequip/documents/2005FranchiseIn dustryReview.pdf. Source: National Restaurant Association.

2. Bowman SA, Vinyard BT. Fast food consumption of US adults: impact on energy and nutrient intakes and overweight status. J Am Coll Nutr. 2004; 23: 163-8.

3. Jeffery RW, French SA. Epidemic obesity in the United States: are fast foods and television viewing contributing? Am J Public Health. 1998; 88: 277-80. doi:10.2105/AJPH. 88.2.277.

4. Pereira MA, Kartashov AI, Ebbeling CA, et al. Fast food habits, weight gain, and insulin resistance (the CARDIA study): 15 year prospective analysis. Lancet. 2005; 365: 36-42. doi:10.1016/S0140-6736(04)17663-0.

5. Mehta NK, Chang VW. Weight status and restaurant availability: a multilevel analysis. Am J Prev Med. 2008; 34: 127-33. doi:10.1016/j.amepre.2007.09.031.

6. Beydoun MA, Powell LM, Wang Y. The association of fast food, fruit and vegetable prices with dietary intakes among US adults: is there modification by family income? Soc Sci Med. 2008; 66: 2218-29. doi:10.1016/j.socscimed.2008.01.018.

7. Chou SY, Grossman M, Saffer H. An economic analysis of adult obesity: results from the behavioral risk factor surveillance system. J Health Econ. 2004; 23: 565-87. doi:10.1016/j. jhealeco.2003.10.003.

8. Cummins SCJ, McKay L, MacIntyre S. McDonald's restaurants and neighborhood deprivation in Scotland and England. Am J Prev Med. 2005; 29: 308-10. doi:10.1016/j. amepre.2005.06.011.

9. Reidpath DD, Burns C, Garrard J, Mahoney M, Townsend M. An ecological study of the relationship between social and environmental determinants of obesity. Health Place. 2002; 8: 141-5. doi:10.1016/S1353-8292(01)00028-4.

10. Block JP, Scribner RA, DeSalvo KB. Fast food, race/ethnicity, and income. Am J Prev Med. 2004; 27: 211-7.

11. MacIntyre S, McKay L, Cummins SCJ, Burns C. Out-of-home food outlets and area deprivation; case study in Glasgow, UK. Int J Behav Nutr Phys Act. 2005; 2: 16-22. doi:10.1186/1479-5868-2-16.

12. Austin SB, Melly Sj, Sanchez BN, Patel A, Buka S, Gortmaker SL. Clustering of fast-food restaurants around school: a novel application of spatial statistics to the study of food environments. Am J Public Health. 2005; 95: 1575-1581.

13. Morland K, Wing S, Diez Roux A, Poole C. Neighborhood characteristics associated with location of food stores and food services places. Am J Prev Med. 2002; 22: 23-29. doi:10.1016/S0749-3797(01)00403-2.

14. Powell LM, Chaloupka FJ, Bao Y. The availability of fast food and full-service restaurants in the United States: associations with neighborhood characteristics. Am J Prev Med. 2007; 33: S240-S245. doi:10.1016/j.amepre.2007.07.005.

15. Burdette HL, Whitaker RC. Neighborhood playgrounds, fast food restaurants, and crime: relationships to overweight in low-income children. Prev Med. 2004; 38: 57-63. doi:10.1016/j.ypmed.2003.09.029.

16. Simmons D, McKenzie A, Eaton S, et al. Choice and availability of takeaway and restaurant food is not related to the prevalence of adult obesity in rural communities in Australia. Int J Obes. 2005; 29: 703-710. doi:10.1038/sj.ijo.0802941. 
17. Sturm R, Datar A. Body mass index in elementary school children, metropolitan area food prices and food outlet density. Public Health Rep. 2005; 119: 1059-1068. doi:10.1016/j.puhe.2005.05.007.

18. Guagliardo MF. Spatial accessibility of primary care: concepts, methods and challenges. Int J Health Geogr. 2004; 3: 3. doi:10.1186/1476-072X-3-3.

19. Gruenewald PJ, Millar AB, Treno AJ, Yang Z, Ponicki WR, Roeper P. The geography of availability and driving after drinking. Addiction. 1996; 91: 967-983. doi:10.1111/j.13600443.1996.tb03594.x.

20. Lipton R, Gruenewald PJ. The spatial dynamics of violence and alcohol outlets. J Stud Alcohol. 2002; 63: 187-195.

21. Rose D, Richards R. Food store access and household fruit and vegetable use among participants in the US Food Stamp Program. Public Health Nutr. 2009; 7: 1081-1088.

22. Cohen DA, Ghosh-Dastidar B, Scribner R, et al. Alcohol outlets, gonorrhea, and the Los Angeles civil unrest: a longitudinal analysis. Soc Sci Med. 2006; 62(12): 3062-3071. doi:10.1016/j.socscimed.2005.11.060.

23. Romley J, Cohen D, Ringel J, Sturm R. Alcohol and environmental justice: the density of liquor stores and bars in urban neighborhoods in the United States. J Stud Alcohol. 2007; 68(1): 48-55.

24. Sastry N, Ghosh-Dastidar B, Adams J, Pebley AR. The design of a multilevel longitudinal study of children, families and communities: the Los Angeles Family and Neighborhood Study. RAND Labor and Population Working Paper DRU-2400/1-LAFANS.2003.

25. Sampson RJ, Raudenbush SW, Earls F. Neighborhoods and violent crime: a multilevel study of collective efficacy. Science. 1997; 277: 918-924. doi:10.1126/science.277.5328.918.

26. Raudenbush SW, Bryk AS, Cheong YF, Congdon R. HLM6.01: Hieararchical Linear and Nonlinear Modeling [software]. Lincolnwood, Ill: Scientific Software International; 2005.

27. Inagami S, Cohen DA, Finch BK. Non-residential neighborhood exposures suppress neighborhood effects on health. Soc Sci Med. 2007; 65: 1779-1791. doi:10.1016/j. socscimed.2007.05.051.

28. Horowitz CR, Colson KA, Hebert PL, Lancaster K. Barriers to buying healthy foods for people with diabetes: evidence of environmental disparities. Am J Public Health. 2004; 94: 1549-1554. doi:10.2105/AJPH.94.9.1549.

29. Zenk SN, Schulz AJ, Israel BA, James SA, Bao S, Wilson ML. Neighborhood racial composition, neighborhood poverty and the spatial accessibility of supermarkets in metropolitan Detroit. Am J Public Health. 2005; 95: 660-667. doi:10.2105/AJPH. 2004.042150.

30. Morland K, Wing S, Diez Roux A. The contextual effect of the local food environment on residents' diets: the Atherosclerosis Risk in Communities Study. Am J Public Health. 2002; 92: 1761-1767. doi:10.2105/AJPH.92.11.1761.

31. Inagami S, Cohen DA, Finch BK, Asch SM. You are where you shop: grocery store locations, weight and neighborhoods. Am J Prev Med. 2006; 31: 10-17. doi:10.1016/j. amepre.2006.03.019.

32. Liu J, Bennett KJ, Harun N, Zheng X, Probst JC, Pate RR. 2007. Overweight and physical inactivity among rural children aged 10-17: a national and state portrait, South Carolina Rural Health Research Center. Accessed on February 11, 2009. Available at: http://rhr.sph.sc.edu/report/SCRHRC_ObesityChartbook_Exec_Sum_10.15.07.pdf

33. MSNBC.com. 2005. "Child Obesity Rising Faster in Rural America." Retrieved from: www.msnbc.msn.com/id/7175066. For the full report see: The Center for Rural Pennsylvania. 2005. "Overweight Children in Pennsylvania." Accessed on February 11, 2009. Available at: www.ruralpa.org/Over weight_child.pdf

34. Tai-Seale T. Chandler. C., 2003. "Nutrition and Overweight Concerns in Rural Areas: A Literature Review. Rural Healthy People 2010: A companion document to Healthy People 2010. Volume 2.” College Station, TX: The Texas A\&M University System Health Science Center, School of Rural Public Health, Southwest Rural Health Research Center. Accessed on February 11, 2009. Available at: http://srph.tamhsc.edu/centers/rhp2010/ 09Volume1nutrition\% 20.htm 
35. Gillum RF, Sempos CT. Ethnic variation in validity of classification of overweight and obesity using self-reported weight and height in American women and men: the Third National Health and Nutrition Examination Survey. Nutr J. 2005; 4: 27. doi:10.1186/ 1475-2891-4-27.

36. Villanueva E. The validity in self reported weight in US adults: a population based crosssectional study. BMC Public Health. 2001; 1: 11. doi:10.1186/1471-2458-1-11.

37. Larson NI, Story MT, Nelson MC. Neighborhood environments: disparities in access to healthy foods in the U.S. Am J Prev Med. 2009; 36: 74-81. doi:10.1016/j.amepre. 2008.09.025.

38. Powell L, Auld M, Chaloupka F, O'Malley P, Johnston L. Access to fast food and food prices: relationship with fruit and vegetable consumption and overweight among adolescents. Adv Health Econ Health Serv Res. 2007; 17: 23-48. doi:10.1016/S07312199(06)17002-8.

39. Maddock J. The relationship between obesty and the prevalence of fast food restaurants: state-level analysis. Am J Health Promot. 2004; 19: 137-143. doi:10.1093/ heapro/dah201.

40. Jeffery RW, Baxter J, McGuire M, Linde J. Are fast food restaurants an environmental risk factor for obesity? Int J Behav Nutr Phys Act. 2006; 3: 2. doi:10.1186/1479-5868-3-2.

41. Zenk S, Powell L. US secondary schools and food outlets. Health Place. 2008; 14: 336346. doi:10.1016/j.healthplace.2007.08.003.

42. Sturm R. Disparities in the food environment surrounding US middle and high schools. Public Health. 2008; 122: 681-690. doi:10.1016/j.puhe.2007.09.004.

43. Lewis L, Sloane D, Nascimento L, et al. African Americans' access to healthy food options in South Los Angeles restaurants. Am J Public Health. 2005; 95: 668-673. doi:10.2105/AJPH.2004.050260.

44. Auchincloss A, Diez Roux AV, Brown DG, Erdmann CA, Bertoni AG. Neighborhood resources for physical activity and healthy foods and their association with insulin resistance. Epidemiology. 2008; 19: 146-157. doi:10.1097/EDE.0b013e31815c480. 